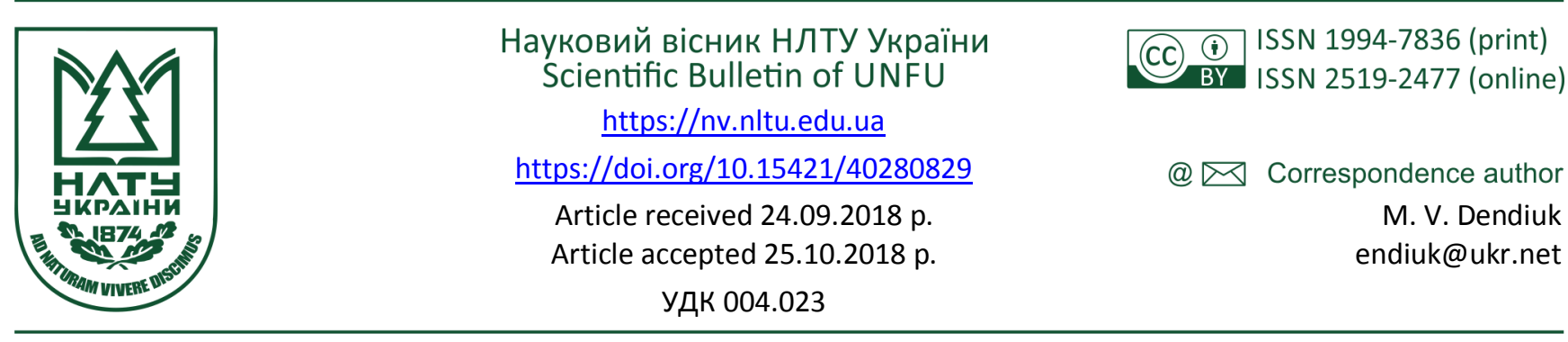

М. М. Подолюх, М. В. Дендюк, С. І. Яцишин

Національний лісотехнічний університет Украӥни, м. Львів, Украӥна

\title{
МАТЕМАТИЧНЕ ТА ПРОГРАМНЕ ЗАБЕЗПЕЧЕННЯ СИСТЕМИ РОЗПІЗНАВАННЯ QR-КОДУ ВІЗИТОК МОБІЛЬНИМИ ПРИСТРОЯМИ
}

Розглянуто проблеми використання QR-кодів. Проаналізовано контент, розміщений у QR-кодах, зазначено переваги та недоліки їх використання. Зазначено, що основними перевагами використання QR-кодів є простота читання їх мобільними пристроями та можливість відновлення інформації, розміщеної в QR-коді, за значних (до 30 \%) пошкоджень коду. Основним же недоліком використання QR-коду є те, що розшифрувати його можна тільки за наявності спеціальних програм. Наведено безкоштовне програмне забезпечення для розпізнавання QR-коду. Зазначено перспективи використання QR-кодів у різноманітних напрямах впровадження. Для вирішення проблеми розміщення в QR-кодах додаткової інформації, зокрема зображення, відео, музики, презентацій тощо, запропоновано новий програмний інтерфейс (АРI), який складається з бази даних та серверної частини. Наведено функціональні можливості АРІ. Використання розробленого АРІ в мобільних додатках для будь-яких операційних систем дає змогу реалізувати єдину систему для зберігання додаткових даних, що на цей момент не використовується у жодній з систем розпізнавання QR-кодів. Розглянуто можливість застосування розробленого API для системи розпізнавання QR-коду візиток мобільними пристроями з OC Android. Для створення такої системи проаналізовано алгоритми розшифрування QR-кодів, наведено її функціонал. Для створення веб-додатку використано трирівневу архітектуру. Наведено прототип додатку та форми, що забезпечують визначений функціонал.

Ключові слова: використання QR-кодів; додаткова інформація; програмний інтерфейс API; веб-додаток.

Вступ. QR-код розробила японська компанія Denso Wave y 1994 p. на заміну штрих-коду. Оскільки у штрих-коді може міститися тільки до 30 символів, тому для збільшення закодованого обсягу інформації та для автоматизації його читання електронними пристроями прийшов QR-код - двомірне зображення, в яке закладається певний контент.

Найменший QR-код (версія 1) має розмір 21×21 піксель, найбільший (версія 40) - 177×177 пікселів. Максимальним контентом, що поміщений в один QR-код, може бути (Tsukanova, 2013):
- цифри
$-7089$
• цифри і букви (включаючи кирилицю)
- двійковий код
- ієрогліфи
$-4296$
-2953 байт;
$-1817$.

Зазвичай контентом QR-коду є текст, інтернет-посилання, e-mail, контактні дані, номери телефонів, SMS, картографічна інформація тощо (Skriabina, 2011).

Використання QR-коду надає певний ряд переваг та недоліків (Chaplinskyi, 2014), аналіз яких показує, що основною перевагою використання QR-коду є простота читання мобільними пристроями. Також великою перевагою QR-коду є те, що завдяки системі корекції помилок інформацію можна розшифрувати навіть в разі 30 \% пошкодження коду (James, 2003).

Основним же недоліком використання QR-кодує те, що розшифрувати його можна тільки за наявності спеціальних програм.

На сучасні смартфони та планшети, що мають вбудовані камери, можна встановити безкоштовне програмне забезпечення для розпізнавання QR-коду:

- I-NIGMA (www.i-nigma.com);

- Kaywa Reader (http://reader.kaywa.com/);

- QuickMark (www.quickmark.cn);

- iMatrix (www.imatrix.lt);

- NeoReader (http://get.neoreader.com).

Перспективи використання QR-кодів у різноманітних напрямах впровадження висвітлено в працях В. Бондаренко (Bondarenko, 2014), Т. Г. Діброва, I. В. Цуканова, (Tsukanova \& Dibrova, 2013), Ковалева А. I. (Kovalev, 2016), В. Логачева (Logachova, 2013), М. Оказакі, М. Хiроші (Okazaki \& Hirose, 2012) тощо. 3 огляду на тотальне поширення мобільних пристроїв та доступності до мережі Інтернет застосування QR-кодів $\epsilon$ актуальним.

Мета дослідження. Створення програмного інтерфейсу (API) та мобільного додатку "Розпізнавання QRкодів на візитних картках", що дасть змогу реалізувати єдину систему для зберігання додаткових даних, що на сьогодні не використовується у жодній із систем розпізнавання QR-кодів.

Програмний інтерфейс надає API-методи розробни-

\section{Інформація про авторів:}

Подолюх Максим Михайлович, магістрант. Email: pomax96@gmail.com

Дендюк Михайло Володимирович, канд. техн. наук, доцент, кафедра інформаційних технологій. Email: dendiuk@ukr.net Яцишин Світлана Іванівна, канд. техн. наук, доцент, кафедра інформаційних технологій. Email: svitlana0981@gmail.com Цитування за ДСтУ: Подолюх М. М., Дендюк М. В., Яцишин С. І. Математичне та програмне забезпечення системи розпізнавання QR-коду візиток мобільними пристроями. Науковий вісник НлтУ України. 2018, т. 28, № 8. C. 146-148.

Citation APA: Podoliukh, M. M., Dendiuk, M. V., \& Yatsyshyn, S. I. (2018). Mathematical software for recognition of QR-code of business cards by mobile devices. Scientific Bulletin of UNFU, 28(8), 146-148. https://doi.org/10.15421/40280829 
ку для будь-якої системи, що спрощує написання багатоплатформних додатків.

Мобільний додаток же 3 допомогою створеного АPI має змогу зв'язати цей додаток з системою та розширює можливості використання QR-коду, зокрема в QR-коді можна розміщувати не тільки символи та цифри, а також зображення, відео, музику, презентації тощо.

Постановка завдання дослідження. Цей програмний продукт має реалізовувати такий функціонал:

Програмний інтерфейс (API) надає змогу:

- створення нового користувача;

- авторизації на підстаі JWT-токена;

- авторизації анонімного користувача;

- створення додаткових даних та прив'язка до QR-коду;

- редагування додаткових даних вже наявного QR-коду;

- видалення додаткових даних QR-коду;

- перегляд усіх створених QR-кодів даним користувачем;

- перегляд збережених QR-кодів з додатковою інформацією;

- редагування інформації про користувача;

- видалення користувача.

Мобільний додаток забезпечує:

- розшифрування QR-коду;

- визначення орієнтації QR-коду;

- генерацію QR-коду;

- реалізацію додаткового функціоналу згідно з АРI.

Розшифрування QR-коду відбувається за таким алгоритмом.

1. Читаємо QR-код, який містить системну інформацію i дані. Системна інформація дублюється, що дає змогу значно знизити ймовірність виникнення помилок під час детектування коду і зчитування. Щоб засвідчити, що прочитано власне QR-код, за шаблоном (International Standard ISO/IEC 18004, 2000) зіставляємо області детектування QR-коду (Position Detection Patterns).

2. Визначаємо формат QR-коду (Format Information) та його версію (Version Information) за маскою. Від коду залежить максимальний обсяг даних, які можуть бути записані в код. Окрім цього, для захисту системної інформації використовується статична маска (таблиця).

Таблиця. Можливі маски

\begin{tabular}{|c|c|}
\hline Код маски & Формула \\
\hline 000 & $(\mathrm{i}+\mathrm{j}) \bmod 2=0$ \\
\hline 001 & $\mathrm{i} \bmod 2=0$ \\
\hline 010 & $\mathrm{j} \bmod 3=0$ \\
\hline 011 & $(\mathrm{i}+\mathrm{j}) \bmod 3=0$ \\
\hline 100 & $((\mathrm{i} \operatorname{div} 2)+(\mathrm{j} \operatorname{div} 3)) \bmod 2=0$ \\
\hline 101 & $(\mathrm{ij}) \bmod 2+(\mathrm{ij}) \bmod 3=0$ \\
\hline 110 & $((\mathrm{i} j) \bmod 2+(\mathrm{ij}) \bmod 3) \bmod 2=0$ \\
\hline 111 & $((\mathrm{i}+\mathrm{j}) \bmod 2+(\mathrm{i} j) \bmod 3) \bmod 2=0$ \\
\hline
\end{tabular}

4. Завдяки корекції ключових слів виявляємо помилки $\mathrm{i}$, якщо вони $\epsilon$, тоді необхідно їх виправити.

5. Визначаємо режим кодування відповідно до правил розташування та відновлення даних у заголовку повідомлення. У роботі реалізовано два режими: числовий і 8-бітний. Числовий - закодовує дані $з$ десяткового набору цифр від 0 до 9, за нормальної щільності 3 символи на 10 біт. У 8-бітний режим кодується набір символів відповідно до JISX0201 unicode. У цьому режимі щільність даних 8 біт на символ.

6. Зчитування виконується змійкою, починаючи з нижньої правої комірки. Старший біт кожного кодового блоку знаходиться у першому доступному розміщені модуля (International Standard ISO/IEC 18004, 2000).

Останнім кроком є розкодування отриманих даних до відповідного режиму.

API-додаток складається 3:

- бази даних (QRcode_DataBase.mdf);
- серверної частини:

- рівень доступу до бази даних (qrcode.dal.dll);

- рівень бізнес-логіки (QRcode.BLL.dll);

- рівень представлення (QRcode.API.dll).

У процесі проектування програмного інтерфейсу було виділено такі сутності: User, Sex, Role, BuisnesCard, Personal, Commercial, Data. Ці сутності зберігаються у відповідних таблицях бази даних.

Для створення веб-додатку використано трирівневу архітектуру. Прототип додатку та форму реєстрації наведено на рис. 1.

Реєстрація користувача необхідна для надавання йому повного функціоналу додатку. Деякі функціональні можливості наведено на рис. 2.

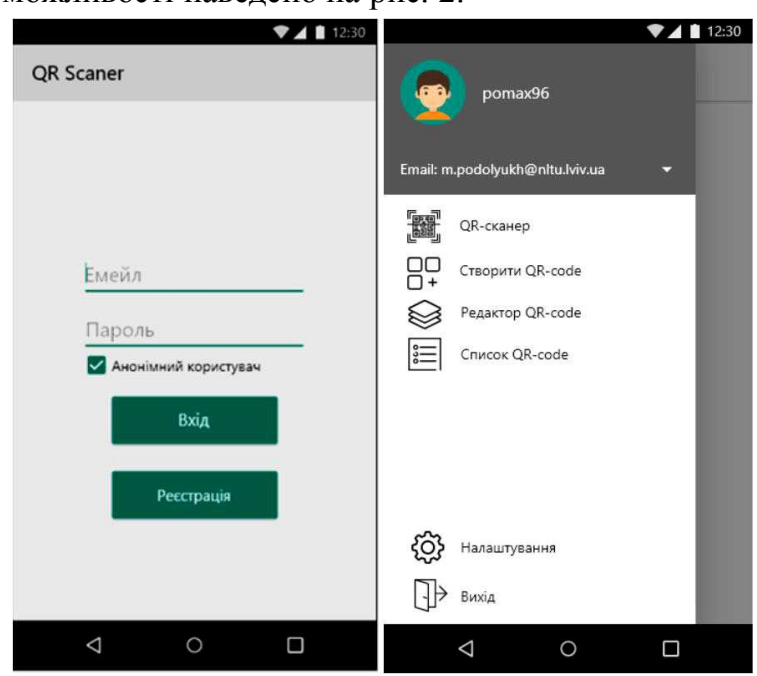

Рис. 1. Головна форма програми та Меню

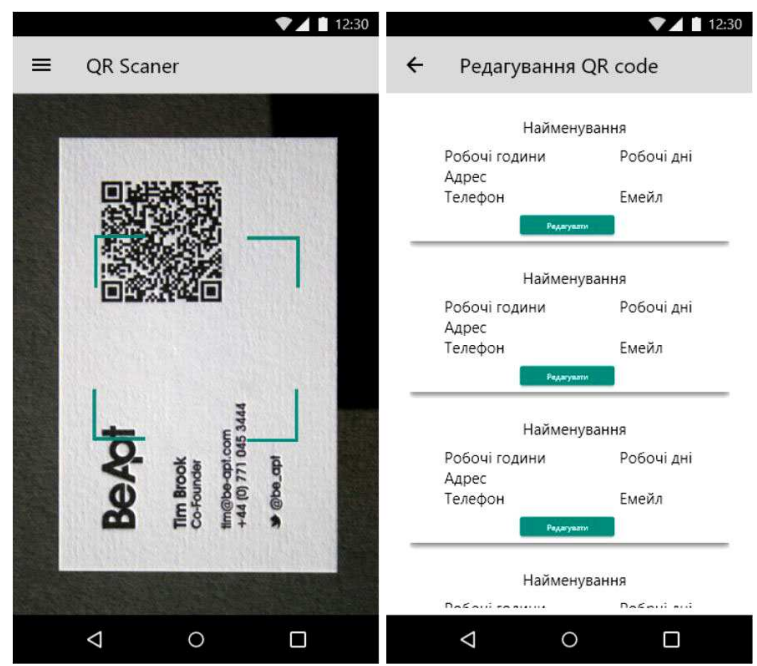

Рис. 2. Функціональні можливості програми QR-сканер та Peдактор QR-коду

Висновки. Отже, на відміну від наявних QR-сканерів, розроблений API надає змогу розширити функціональні можливості під час написання програм не тільки для розпізнавання QR-коду візиток мобільними пристроями, їх створення, але й використання додаткових даних і реалізацію їх прив'язки до QR-коду.

\section{Перелік використаних джерел}

Bondarenko, V. (2014). Mobilni tekhnolohii u bibliotetsi: QR-kod. Bibliotechnyi visnyk, 6, 28-32. [In Ukrainian].

Chaplinskyi, Yu., \& Manhul, A. (2014). QR-kod yak suchasnyi zasib $v$ marketynhovykh komunikatsii. Retrieved from: http://www.rusnauka.com/2 KAND 2015/Economics/ 6 185617.doc.htm. [In Ukrainian]. 
International Standard ISO/IEC 18004. (2000). Information technology - Automatic identification and data capture techniques - Bar code symbology - QR Code. Retrieved from: https://www.swisseduc.ch/informatik/theoretische informatik/qr_codes/docs/qr_standard.pdf.

James, S. Plank. (2003). GFLIB - C Procedures for Galois Field Arithmetic and Reed-Solomon Coding. Retrieved from: http://web.eecs.utk.edu/ plank/plank/gflib/.

Kovalev, A. I. (2016). QR-kody, ikh svoistva i primenenie. Molodoi uchenyi Mezhdunarodnyi nauchnyi zhurnal, 10.1(114.1), 56-60. [In Russian].
Logachov, V. (2013). Shto neset QR-kod. Retrieved from: http://www.ridcom.ru/ publications/131/. [In Russian].

Okazaki, S., Li, H., \& Hirose, M. (2012). Benchmarking the Use of QR Code in Mobile Promotion. Three Studies in Japan. Journal of Advertising Research, 102-117.

Skriabina, Anna. (2011). 20 sposobov ispolzovania QR-kodov. Retrieved from: http:/www.lookatme.ru/flow/posts/internet/117583-20sposobov-ispolzovaniya-qr-kodov. [In Russian].

Tsukanova, I. V., \& Dibrova, T. H. (2013). Osoblyvosti zastosuvannia QR-kodu v intehrovanykh marketynhovykh komunikatsiiakh. Ekonomichnyi visnyk Natsionalnoho tekhnichnoho universytetu Ukrainy "Kyivskyi politekhnichnyi instytut", 49, 429-434. [In Ukrainian].

М. М. Подолюх, М. В. Дендюк, С. И. Яцишин

Национальный лесотехнический университет Украины, г. Львов, Украина

Рассмотрены проблемы использования QR-кодов. Проанализирован контент, размещенный в QR-кодах, указаны преимущества и недостатки их использования. Отмечено, что основными преимуществами использования QR-кодов является простота чтения их мобильными устройствами и возможность восстановления информации, размещенной в QR-коде, при значительных (до 30 \%) повреждениях кода. Основным же недостатком использования QR-кода является то, что расшифровать его можно только при наличии специальных программ. Приведено бесплатное программное обеспечение для распознавания QR-кода. Указаны перспективы использования QR-кодов в различных направлениях внедрения. Для решения проблемы размещения в QR-кодах дополнительной информации, в частности изображения, видео, музыки, презентаций и т.д., предложен новый программный интерфейс (API), который состоит из базы данных и серверной части. Приведены функциональные возможности API. Использование разработанного АРI в мобильных приложениях для любых операционных систем дает возможность реализовать единую систему для хранения дополнительных данных, что на данный момент не используется ни в одной из систем распознавания QR-кодов. Рассмотрена возможность применения разработанного API для системы распознавания QR-кода визиток мобильными устройствами с OC Android. C целью создания такой системы проанализированы алгоритмы расшифровки QR-кодов, приведен ее функционал. Для создания веб-приложения использована трехуровневая архитектура. Приведен прототип приложения и форм, обеспечивающих определенный функционал.

Ключевые слова: использование QR-кодов; дополнительная информация; программный интерфейс API; веб-приложение.

M. M. Podoliukh, M. V. Dendiuk, S. I. Yatsyshyn

Ukrainian National Forestry University, Lviv, Ukraine

\section{MATHEMATICAL SOFTWARE FOR RECOGNITION OF QR-CODE} OF BUSINESS CARDS BY MOBILE DEVICES

The problems of using QR codes are considered. The content, coded in QR-codes, is analyzed; advantages and disadvantages of their use are mentioned. The main advantages of using QR-codes is noted to be the ease of reading of their mobile devices and the possibility of restoring information contained in the QR-code, with significant, up to $30 \%$ of code damage. The main drawback of using QR-code is that it can be decrypted only if there are special programs. The authors provide free software for QR code recognition. The prospects of using QR-codes in different directions of implementation are indicated. To solve the problem of placing additional information in QR-codes, such as images, videos, music, presentations, etc., we propose a new API (API) that consists of a database and a server part. The API features include the creation of a new user, JWT-authorization, anonymous user authorization, creation of additional data and QR-code binding, editing of additional data for an existing QR code, removal of additional QR-code data, viewing all generated QR-codes by the user, viewing saved QR-codes with additional information, editing user information and deleting the user. In the process of designing the UI, the following entities were highlighted: User, Sex, Role, Business Card, Personal, and Commercial Data. These entities are stored in the corresponding database tables. The server-side functionality provides the level of access to the database (qrcode.dal.dll), the level of business logic (QRcode.BLL.dll), and the level of representation (QRcode.API.dll). The use of the developed API in mobile applications for any operating system provides the ability to implement a single system for storing additional data that isn't currently used in any of the QR code recognition systems. The possibility of application of the developed API for the system of recognition of QR code of business cards by mobile devices with Android operating system is considered. In order to create such a system, algorithms for decoding QR-codes are analyzed, its functionality being given. Three-tier architecture is used to create a web application. The prototype of the application and forms providing the defined functionality are given.

Keywords: use of QR codes; Additional Information; API; web application. 